\title{
edmetic
}

Revista de Educación Mediática y TIC

\section{De la tecnología lingüística, o cómo utilizar las TIC para aprender otras lenguas}

\section{From linguistic technology, or how to use ICT to learn other languages}

\author{
Verónica Marín-Díaz \\ Universidad de Córdoba (España) \\ vmarin@uco.es
}

Aprender otra lengua puede llegar a convertirse en una pesadilla o un reto. Si nos posicionamos en la idea de que es una pesadilla considero que jamás avanzaremos más allá del típico «hello» o «comment ça va?»», y nuestro cerebro se bloqueará y negara a aprender.

Si nos centramos en que es un reto, nuestra perspectiva será más amplia. Cómo aprendices de una segunda lengua 0 de una lengua extranjera, buscaremos los recursos que mejor se adapten a nuestra realidad tanto económica, como social, -entendiendo esta por el tiempo qué se dispone para 'estudiar'-, y académica.

Desde esta última vertiente, los centros educativos, deben responder a una nueva realidad que la sociedad plantea, que no es otra que la necesidad de que los estudiantes, salgan de sus aulas lo mejor formados en otra lengua diferente a la autóctona o materna. En esta línea el Marco Común Europeo de Referencia para las Lenguas (MERCL) propugna el empleo de las Tecnologías de la Información y la Comunicación (TIC) para el aprendizaje de un idioma. Pues de lo que se trata en general es que la lengua materna no interfiera en el aprendizaje de la segunda lengua, tratando de superar los resultados de investigaciones como la de Gökşenli (2017), quien indicaban que los estudiantes turcos o húngaros tenían dificultades en el aprendizaje del español por interferencias de sus propias lenguas.

En esta línea inmersiva encontramos el estudio desarrollado por Mira (2018) sobre el empleo del Portfolio Europeo de las Lenguas Electrónico o e- 
PEL, que pone de relieve como la utilización de recursos digitales mejora sustancialmente el conocimiento lingüístico de los estudiantes.

También podemos situarnos en aplicar la metodología del Aprendizaje Integrado de Contenidos y Lenguas Extranjeras reconocida por sus siglas AICLE, si bien también se puede identificar con las siglas en inglés CLIL (Content and Language Integrated Learning) o en ÉMILE (Enseignement de Matières par I'Intégration d'une Langue Étrangère) apoyado en TIC. En esta línea se encuentra el trabajo de Carrión (2018), quien combinando el empleo de un blog (http://elrincondemusicaycine.blogspot.com/) con la música y la segunda lengua, en este caso el inglés. Su mayor aportación consiste en buscar intereses comunes de los alumnos de secundaria (TIC+música) que despierten el interés por la tercera pata de su apuesta el idioma. También podemos ver como empleando una combinación de varios recursos digitales como son los podcast, los códigos QR y los Smartphone podemos propiciar el aprendizaje lingüístico, como recogen Samoano y Menéndez (2018) en su trabajo.

En cualquier caso, esta metodología al igual que la anterior se apoya en el empleo de recursos digitales para la mejora del aprendizaje del idioma por parte del estudiante.

En general las aportaciones centradas en TIC+lenguas extranjeras presentan el mismo hándicap, la necesidad de un mayor tiempo de aplicación para obtener resultados significativos (Checa-García, 2017), en lo que se refiere al aprendizaje autónomo del alumno, competencia básica en todos los niveles educativos, como defienden Ruipérez, Cabrero y Palazio (2017).

Por otra parte, no debemos dejar de lado la figura del docente, principal responsable del proceso de enseñanza-aprendizaje. Es este quien debe motivar al alumnado, para que se encuentre motivado en el aprendizaje del idioma, y de mostrarle las virtudes de la lengua a la que se quiera incorporar como parlante. Comunidades de prácticas como la que presentan Bedoya, Betancourt y Villa (2018), quienes tras dicha práctica han propiciado un lugar de encuentro y generación de materiales para docentes que imparten docencia de otras lenguas. 
Por último, no podemos dejar de lado el universo de APP creadas para dispositivos móviles (Smartphone y Tablet), principalmente, el cual ha ido creciendo significativamente. No es mi intención posicionarme por una en concreto, pues todas ellas tienen las mismas ventajas e inconvenientes en primera instancia, a mi juicio, no obstante la mayor convergencia que tienen todas, es el tiempo.

En consecuencia, nos debemos dejar de considerar estás limitaciones, así como su aplicación e implicación en el diseño de las metodologías de aula que promuevan esta formación. Cabe situarse en una motivación continua como aporta Lamar (2016), en pro de una mejora de lo aprendido y de lo que se aprenderá.

\section{Referencias}

BEDOYA, J.R., BETANCOURT. M.O., y VILLA, F.L. (2018). Creación de una comunidad de práctica para la formación de docentes en la integración de las TIC a los procesos de aprendizaje y enseñanza de lenguas extranjeras. íkala, Revista de Lenguaje y Cultura, 23(1), 121-139. doi: 10.17533/udea.ikala.v23n01a09

CARRIÓN, E. (2018). Experiencias TIC en la enseñanza bilingüe mediante recursos digitales musicales. DIM, Didáctica, Innovación y Multimedia, 36.

Recuperado de https://www.raco.cat/index.php/DIM/article/view/335144/425930

CHECA-GARCÍA, I. (2016). Prosodic Cues in Relative Clauses Disambiguation: Bilinguals vs. L2 Learners. NAER, New Approaches in Educational Research, 5(2), 74-80, doi: 10.7821/naer.2016.7.168

GÖKŞENLI, E.Y. (2017). Análisis contrastivo de errores en el aprendizaje de ELE de alumnos de lengua materna alemana y turca. INNOEDUCA. International Journal of Technology and Educational Innovation, 3(1), 5765. doi: http://dx.doi.org/10.24310/innoeduca.2017.v3i1.1967

LAMAR, C. (2016) On Teaching the History of California Spanish to HLL using Siri: Methodology and Procedures. NAER, New Approaches in Educational Research, 5(2), 107-114. doi: 10.7821/naer.2016.7192

MIRA, M.J. (2018). Cambio de perspectiva en el aprendizaje de lenguas extranjeras: hacia la autonomía con el e-PEL (Portafolio Europeo de las 
Lenguas Electrónico). Bordón, 70(2), 73-86. doi: http://doi.org/10.13042/Bordon.2018.56676

RUIPEREZ, G., CABRERO, J.C., Y PALAZIO, G. (2017). Strategies for fostering autonomous language learning through the use of mobile devices (mobile learning). IJERI, International Journal of Educational Research and Innovation, 8, 281-292. Recuperado https://www.upo.es/revistas/index.php/IJERI/article/view/2427

SAMOANO, Y., y MENÉNDEZ, J.I. (2018). Percepciones de alumnado y profesorado sobre una intervención de mobile learning en inglés como lengua extranjera. INNOEDUCA. International Journal of Technology and Educational Innovation, 3(1), 57-65. doi: http://dx.doi.org/10.24310/innoeduca.2018.v4i1.3024 